\section{Estudo \\ Ecidebate}

em Testã⿻

Plamejamento
Revista Estudo \& Debate, Lajeado, v. 28, n. 3, 2021. ISSN 1983-036X

DOI: http://dx.doi.org/10.22410/issn.1983-036X.v28i3a2021.2924

\title{
PAISAGEM CULTURAL E AS FAZENDAS DO PIAUÍ/BRASIL - SÉCULOS XVII-XX
}

\author{
Neuza Brito de Arêa Leão Meloº , Neli Teresinha Galarce Machado²
}

\begin{abstract}
Resumo: As fazendas estabelecidas entre os séculos XVII e XX são os alvos da presente pesquisa, por serem, ao longo do tempo, grandes motivadoras econômicas e indutoras da formaçáo do Piauí e, ainda, da urbanização de algumas das cidades mais antigas do Estado. A partir de seu estudo, busca-se compreender as diversas formas de adaptação e transformação do meio ambiente, além de dar visibilidade e reconhecimento ao patrimônio rural piauiense e sua paisagem cultural. Desse modo, objetiva-se apresentar um contexto geral das fazendas do Piauí, fundadas entre os séculos XVII e XX a partir da arquitetura e das relaçóes ambientais e históricas entre os diversos sujeitos e espaços, por meio da compreensão dos aspectos contextuais envolventes e de alguns conceitos norteadores. Essa pesquisa tem perfil exploratório, é descritiva e explicativa, utilizando-se da pesquisa bibliográfica e documental. A partir da análise feita constatou-se a relevância desses espaços na produção de lugares e de paisagens culturais que envolvem o pensar acerca do meio ambiente piauiense.
\end{abstract}

Palavras-chave: Fazendas. Meio ambiente. Arquitetura. História. Paisagem Cultural.

\section{CULTURAL LANDSCAPE AND THE PIAUÍ/BRASIL FARMS - 17th- 20th CENTURIES}

\begin{abstract}
The farms estabilished between the 17th and 20th centuries are targets of the present research, for being, over time, big economic motivators and inductors of Piauís formation, and, yet, of the urbanization of some of the oldest cities in the state. Based on its study, it seeks to understand the different ways of adapting and transforming the environment, in addition to giving visibility and recognition to Piauís rural heritage and its cultural landscape. Thus, the objective is to present a genereal context of the state's historic farms, founded between the 17th and 20th centuries, from architecture and environmental and historical relationships among the different subjects and spaces, through the understanding of the surrounding contextual aspects and some of the guiding concepts. This research has an exploratory profile, is descriptive and explanatory, using bibliographic and documentary research. From the analysis made, it was found the relevance of these spaces in the production of places and cultural landscapes that involves thinking about the state's environment.
\end{abstract}

Keywords: Farms. Environment. Architecture. History. Cultural Landscape.

1 Arquiteta; Doutoranda do Programa de Pós-graduação em Ambiente e Desenvolvimento da Universidade da Vale do Taquari/RS.

2 Docente do Programa de Pós-graduação em Ambiente e Desenvolvimento da Universidade da Vale do Taquari/RS. 


\section{Introdução}

A paisagem cultural piauiense é, de modo relevante, constituída por suas fazendas, sua arquitetura, suas formas de vivência, a percepção do local e as políticas públicas associadas a esses espaços. Deste modo, constituem-se como objeto desse estudo a história das fazendas, erguidas entre os séculos XVII e XX, analisadas como contribuintes da transformação do meio e da formação das nucleaçóes urbanas mais antigas do Estado.

$\mathrm{O}$ estudo pretende destacar como essas fazendas foram e ainda são grandes motivadores econômicos no Estado, bem como de grande relevância para a ocupação do Sertão e para a formação da identidade espacial, organizando a dinâmica urbana, as relaçôes sociais e, desta forma, parte da paisagem cultural que hoje se apresenta.

Esses complexos já tiveram e ainda têm papel importante, não só na economia, mas em outros aspectos de suma relevância, como a transformação do meio ambiente, a ocupação do território, a criação de espaços, o que leva a buscar entender as relaçóes diversas, os entendimentos distintos sobre como atuar e usufruir não só desse patrimônio, tão caro para a memória e identidade, mas principalmente do meio ambiente.

Nessa perspectiva, a história aponta que o Estado do Piauí foi conformado a partir dos núcleos rurais implantados, principalmente, entre os séculos XVII e XX. Ela permite inferir, ainda, que esses espaços foram transformados em razão de diversas condicionantes, como a econômica e natural, por exemplo. Por isso, por meio de análise e estudos comparativos sobre a trajetória histórica e construtiva das fazendas nas terras piauienses, a demonstração da potencialidade e da singularidade do "lugar" rural, da paisagem cultural, em um cenário econômico e socioambiental, passa a ser ponto importante para a representatividade do patrimônio cultural regional e sua paisagem.

Inicialmente, justifica-se a pesquisa pela necessidade cada vez maior de dar visibilidade e reconhecimento ao patrimônio rural piauiense, à paisagem, sobretudo, à criada a partir da pecuária e do ciclo do gado vacum, o que implica na adaptação e transformação do meio ambiente.

Espera-se com este estudo contribuir para o conhecimento da formação do estado do Piauí, e assim, das políticas públicas associadas à preservação ambiental; oferecer contributos para avaliação dessas políticas públicas, rurais e/ou urbanas, setoriais e específicas, que resultam na preservação do patrimônio cultural do ambiente rural, espaço dessa pesquisa. Também colaborar para que a paisagem cultural piauiense seja mais estudada e valorizada, para que os profissionais tenham base, fontes de estudo e pesquisa que possibilitem melhor desenvolvimento dos trabalhos, e, por fim, para que haja maior conscientização quanto à importância da preservação dessas fazendas.

\section{Metodologia}

A área de estudo pesquisada envolveu grande parte do atual Estado do Piauí, posto que as fazendas, os objetos de estudo, surgiram, principalmente, a partir de sua ocupação ao longo dos séculos. A pesquisa aqui apresentada, quanto a seus objetivos, tem perfil exploratório, pois busca conhecer mais sobre o patrimônio cultural rural e a paisagem 
piauiense, na busca por fornecer informaçóes que possam contribuir o melhor conhecimento e usufruto do meio ambiente.

$\mathrm{O}$ presente trabalho traz a abordagem descritiva. Quanto à metodologia a ser utilizada para a elaboração da pesquisa foram utilizados métodos de pesquisas consubstanciados, principalmente, em pesquisa bibliográfica, que veio, inicialmente, no processo, com o intuito de recolher dados que propiciem a revisão bibliográfica e o entendimento, sobretudo, da área objeto de estudo, bem como os instrumentos de proteção e gestão do lugar. Buscaramse informaçóes para o embasamento do trabalho, dados sobre a paisagem formada, sobre os fatos históricos e atuais envolvendo aspectos políticos, sociais e culturais pertinentes ao tema, utilizando de documentos disponíveis em sites como do Instituto do Patrimônio Histórico e Artísitico Nacional ${ }^{3}$ e sites de prefeituras do estado do Piauí.

\section{Referencial Teórico}

A história do Piauí, ainda no século XVI, está ligada, de início, ao processo de ocupação do sertão, ao apresamento do gado vacum e de indígenas. Esta região demorou a ser desbravada, mesmo com a colonização do Brasil tendo sido iniciada naquele século.

De acordo com o que traz o IPHAN (2009), a região litorânea setentrional, que se estende do Rio Grande do Norte até o delta do rio Parnaíba, não despertou interesse suficiente por parte da Coroa Portuguesa nem de outras naçóes europeias - à exceção dos franceses, que, desde o século XVI, que já praticavam escambo com indígenas da costa cearense e maranhense e da Serra da Ibiapaba - para a exploração econômica, por não ser boa ao cultivo da cana-de-açúcar e pela dificuldade de navegação entre Maranhão e Pernambuco, sendo inclusive mais viável e menos demorado realizar este percurso por Lisboa, como atestam várias expedições documentadas entre os séculos XVI e XVII.

As primeiras notícias do Piauí vêm, principalmente, através do rio Parnaíba, ainda pelos anos de 1587, quando começaram as informaçóes sobre o mesmo ser navegável. No século XVII, já em 1603, tem-se notícia do português, o capitão-mor Pero Coelho de Sousa, passando por terras piauienses em direção à Serra da Ibiapaba para perseguir indígenas e alguns franceses. Em 1607, os jesuítas Francisco Pinto e Luiz Figueira, seguidos por indígenas vindos de barco do Pernambuco, também teriam, em certo momento, desembarcado na regiáo do Piauí. Esse é um primeiro registro dos padres na regiáo do litoral piauiense, e também em Viçosa, no Ceará - onde se instalaram posteriormente, em 1691, sendo suas passagens pelo Piauí rápidas e transitórias. (FRANCO, 1977).

Por ter seu processo de colonização ocorrido posteriormente e do Interior para o litoral, até meados do século XVII, em 1640, o Piauí não aparecia nos mapas, e o rio Parnaíba, chamado de rio Pará, à época, pertencia ao Ceará. A partir da expulsão dos holandeses, ainda na primeira metade do século XVII, a indústria açucareira entrou em crise, dando início a escassez de produtos de consumo no litoral, gerando reflexos negativos à economia e às finanças da Corte, criando um dos mais fortes estímulos para a conquista do Sertão, pois dele sairiam novas fontes de enriquecimento. Os portugueses procuraram um

3 http://portal.iphan.gov.br/pagina/detalhes/617. Acessado em abril de 2021. 
local mais seguro para a criação de gado, ficando o rio São Francisco como um limite entre as duas atividades: a agricultura canavieira, voltada para o litoral, e a atividade criatória, voltada para o Interior.

De acordo com Arraes (2016), até o final do século XVII, pouco se conhecia sobre o território que, posteriormente, passou a ser o Piauí. As informaçóes eram, em maioria, frutos de relatos fragmentados, feitos ou escritos por religiosos, indígenas e sertanistas, que, por vezes, tratavam os sertôes como terras de riquezas, com profusão de minerais, mas por outras, o lugar da barbárie.

Assim, alguns desbravadores, com anuência da Coroa Portuguesa, partiram em busca de metais preciosos e apresamento de indígenas, começando suas penetraçóes aos sertóes. Inicialmente os bandeirantes saíram de Sáo Paulo, descendo o rio das Velhas e, em seguida, o São Francisco e, posteriormente, enveredaram pela margem direita do rio Parnaíba, penetrando no território que viria a se constituir a Capitania do Piauí que, segundo Porto (1974), teve esse nome em função de um dos rios da regiáo, o Piauí, que, por sua vez, era referência obrigatória das entradas sertanejas.

Alguns historiadores, como Chaves (1994), afirmam que, em 1662, o bandeirante paulista Domingos Jorge Velho, teria saído de São Paulo e chegado ao Piauí, à barra do rio Poti, onde teria fundado algumas fazendas de gado e, posteriormente, foi implantada sua atual capital, Teresina. Destaque-se, nesse momento, o papel da Casa da Torre, na Bahia, de propriedade do português Garcia D’Ávila, que chegou ao Brasil em 1549, na expedição de Tomé de Sousa, trazendo as primeiras cabeças de gado da ilha do Cabo Verde, na Índia, fundando o primeiro curral de vacas da Bahia, de onde se espalharam por todo o sertáo, tornando-se um dos maiores latifúndios da colônia em busca da exploração da pecuária extensiva. A Casa da Torre foi, assim, a casa central de uma sesmaria, com área geográfica que compreendia terras desde Salvador até o vale do rio Itapecuru no atual Estado do Maranhão, incluindo, por conseguinte, o Piauí (RODRIGUES, 2005).

Passaram a existir duas maiores rotas de penetração, ao que depois se tornou o Piauí. A entrada pelo Sertão de Rodelas, que já era marco de trilhas migratórias das tribos nômades que adentravam pelo Piauí em direção ao litoral, sendo também uma referência para o colonizador europeu para instalaçấo de novos currais, trajeto que ficou mais conhecido como Sertáo-de-dentro. O outro trajeto existente, este saindo de Pernambuco e da Paraíba, em direção ao rio Parnaíba, foi denominado Sertão-de-Fora.

Silva Filho (2007) já elenca trinta fazendas de gado no Piauí em 1674. Contudo, para Rodrigues (2005), Domingos Afonso Mafrense, neste mesmo ano, teria sido o verdadeiro responsável pela conquista do lugar, ocupando definitivamente o solo do Piauí, enquanto os outros exploradores náo se fixaram e estiveram apenas de passagem, inclusive Domingos Jorge Velho. Mafrense era associado a Francisco Dias D’Ávila, sucessor de Garcia, e um dos responsáveis pela grande bandeira que adentrou pelo sertão do Piauí, fundando várias fazendas de gado. Mafrense teria adentrado a regiāo fundando sua principal fazenda, a Cabrobó. Carvalho (1697) atesta que em 1682, o povoado do Piauí já contava com fazendas de gado nos vales dos rios Gurguéia, Piauí, Canindé, Poti e Longá. Assim, os vaqueiros adentraram terras desconhecidas, promovendo uma ocupação espontânea e não oficial. 
No final do século XVII, os conquistadores transformaram-se em curraleiros, tendo o gado como moeda da nova era. $\mathrm{O}$ gado vacum dispensava a proximidade com o litoral, davase bem em regiôes impróprias ao cultivo da cana-de-açúcar, servia de transporte, não exigia mão de obra especializada, nem capital fixo ou circulante, com capacidade de multiplicação, além de alimentar um grande número de pessoas de uma só vez (ABREU, 1998).

Até meados do século XVIII, a unidade da organização piauiense foi a fazenda, onde as famílias viviam isoladas em função da atividade de criação de gado em regime extensivo. Das primeiras freguesias criadas, como a de Cabrobó, muitos desceram os afluentes do Parnaíba e fundaram centenas de currais de gado. Após o domínio dos indígenas, foram os caminhos criados a partir da expansão da pecuária e, posteriormente, a fundação de vilas necessárias para o controle da circulação da economia por parte da Coroa Portuguesa, que assegurou a estruturação do território piauiense.

O vaqueiro, personagem importante na formação dessa história, é fruto da mestiçagem entre o colonizador europeu, o indígena catequizado e o negro cativo, pois a mão de obra escravizada foi presença marcante na lida do gado, mesmo sem a presença das senzalas, e com mais laços de gregarismo entre fazendeiros, vaqueiros, cabras e pessoas escravizadas.

Quanto aos escravizados, Sousa (2008) discute que a pecuária piauiense se estabeleceu no contexto do escravismo brasileiro de modo original. Nesse contexto, os escravizados e o gado representavam grande parte do capital investido na empresa de criação, mas a força de trabalho escravo nâo tinha o mesmo caráter empregado na produção do açúcar, pois o relacionamento entre o "senhor" (ou do vaqueiro) e o escravizado era direto, não existindo, via de regra, a figura do feitor ou capataz, além de não exigir a especialização do trabalho. Desta forma, os indivíduos escravizados se ocupavam de várias e distintas tarefas que iam de vaqueiro à fábrica (ajudante do vaqueiro).

Em 1694, o Bispo Diocesano de Pernambuco ordenou a criação de uma freguesia no Piauí. Em 1695, o padre visitador, Miguel de Carvalho, relatou que em 1697, no Piauí já existiam 129 fazendas de gado, nas quais moravam 441 pessoas, entre brancos, negros cativos, indígenas pacificados, mulatos e mestiços (CARVALHO, 1697), o equivalente a 3,4 pessoas por fazenda.

Percebe-se a ocupação rarefeita, marcada por grandes domínios. O termo fazenda, relacionado à criação sertaneja, refere-se, a princípio, às grandes porções de terra distribuídas pela Coroa, aos latifúndios compostos de dezenas de léguas. Mas as fazendas pertenciam às grandes áreas reconhecidas oficialmente por Sesmarias. Conforme Silva (1997), o objetivo primeiro dos desbravadores ao lutar pelas enormes sesmarias era arrendar as terras recebidas, e Mott (1985) reforça que poucas eram as fazendas que recebiam administração direta de seus donos, a maioria delas estava sob a responsabilidade de vaqueiros.

Assim, conclui-se que as grandes áreas de sesmarias eram divididas em fazendas, espaços ligados às condiçóes dos recursos hídricos, vastos pastos e currais (cercados de madeira de lei ou com muros de pedra para receber o gado) e cuja extensão dependia do tamanho do rebanho e de sua produção; e os sítios eram terras arrendadas onde, de acordo com Mott (1985), também se desenvolvia o cultivo para subsistência. 
Para Alves (2019), a ausência dos proprietários ocorreu devido às precárias condiçôes de vida nos sertôes. A distância entre as fazendas, o perigo dos ataques indígenas e a comunicação com os centros urbanos litorâneos eram quase inexistentes, acentuando o isolamento. Silva Filho (2007) explica que a agricultura era de subsistência, explorada apenas para o sustento doméstico e para a sustentação das tropas com a produção de insumos como farinha e milho. As terras eram deixadas para a pecuária, e produtos como sal, ferragens, notícias, tecidos ou outras amenidades eram trocados por produtos da pecuária, quando da passagem das tropas que vinham do Maranhão, Ceará ou da Bahia.

\section{Resultados e Discussóes}

A opção pela vida nas fazendas resultou, a princípio, na quase ausência de núcleos urbanos nos anos iniciais do povoamento daquela área, quando os habitantes não optavam pela vida nas cidades. Faz-se importante relembrar a necessidade da proximidade com os cursos d'água ou a possibilidade de acesso ao líquido, referência para a fixação do homem a terra, e onde se instalaram sítios, fazendas de gado e, em seguida, a maioria das aglomeraçóes urbanas.

Aos poucos, foi se formando a configuração espacial do Piauí, ligada diretamente à atividade criatória. Ao observar os limites territoriais do Estado, percebe-se o alargamento no interior e o afunilamento à medida que se aproxima do litoral. Quando das primeiras sesmarias, e mesmo com a insistência dos colonizadores em evitar a caatinga, alegando não haver nas terras pastos bons suficientes, aos poucos, foram se acomodando nestas (ABREU, 1998).

Silva Filho (2007) enfatiza que nas fazendas, enquanto primeiros assentamentos, além da proximidade com os brejos, olhos d'água e forraçôes, não havia estrutura para a família do colonizador, sendo as moradas toscos e provisórios arcabouços, casas rústicas de taipa e cobertura de duas águas estruturada com carnaúba. Contudo, os currais eram imprescindíveis, assim como as casas de farinhada e oficinas de carpintaria e selaria.

Nos sítios, quando independentes das fazendas, induz-se a pensar que existiam proprietários neles domiciliados. A partir dos anos 1700, quando ocorreu uma maior subdivisão das grandes propriedades, houve também certa reversão do absenteísmo nas fazendas, antecedendo a criação de vilas. Para tanto passou a ser necessário o maior conforto das moradias, e ainda, as relaçóes de vizinhança e assistência espiritual (SILVA FILHO, 2007).

No começo do novo século, dos 1700, inicia-se uma política de incentivo à ocupação efetiva do território e, assim, a fundação de povoaçóes oficiais, de onde se poderia controlar, fiscalizar e vigiar áreas fragilmente delimitadas e senhoreadas por uma poderosa rede de homens residentes ao longo de toda a região, desde o Sertão de Rodelas, ao litoral.

Grande importância tiveram os representantes da Companhia de Jesus na penetração desse território. Liderados por Manoel da Nóbrega, chegaram à Colônia em 1549, com Tomé de Sousa. Foram os pioneiros das ordens com a principal funçáo de evangelizar, catequizar e tornar cristáos os indígenas que habitavam estas terras, estabelecendo-se, dentre outros lugares, desde 1691 em Viçosa do Ceará, na Serra da Ibiapaba (IPHAN, 2009). 
Assis (2012) comenta que, em 1711, quando da morte de Mafrense, parte de seu espólio, que incluía dezenas de fazendas, pessoas escravizadas, gado bovino e cavalar, entre os vales do São Francisco e Parnaíba, ao longo dos leitos do Canindé e Piauí, foi deixado em herança para os padres jesuítas. Foi então que os inacianos tornaram-se os maiores latifundiários do Piauí. Apesar da construção de uma capela e um hospício na Vila da Môcha, a primeira do estado, não foram estabelecidas grandes igrejas ou colégios, pois a ocupação era rarefeita no território piauiense, um deserto pontilhado com concentração da população e do gado (IPHAN, 2009).

Aqueles que eram herdeiros minoritários de senhores de engenho, ou indivíduos livres despossuídos de patrimônio e prestígio social, ou ainda escravizados fugidos, aos poucos foram sendo atraídos pela pecuária, o que demandou aumento populacional, e, consequentemente de mais freguesias, e depois das vilas (IPHAN, 2009).

De atividade subsidiária da economia açucareira, a pecuária, com a produção de gado de corte, tornou-se a base da economia piauiense, a partir da formaçáo de uma rede destinada ao abastecimento do mercado interno. Os rebanhos dos sertóes piauienses eram dos mais numerosos de toda a Colônia em razão da perenidade dos campos e pastos, servindo para abastecer, inclusive, fazendeiros do Ceará e do médio e alto São Francisco, quando da ocorrência de estiagens prolongadas. A pecuária tornou-se responsável, ainda, pelo surgimento de várias freguesias e vilas no Piauí, formadas ao longo dos caminhos percorridos pelas boiadas em destino aos centros consumidores.

Nos anos de 1720, 1730, quando, de acordo com Silva Filho (2007), já existiam cerca de 400 fazendas de gado na regiáo, surgiu a indústria do charque, processo de salga que consistia na carneação, salga e secagem das mantas de carne. Anteriormente, as perdas do rebanho eram muito grandes. Quando as boiadas seguiam os cursos dos rios para abastecer os principais mercados estabelecidos no Maranhão, Grão-Pará, Pernambuco, Bahia, Rio de Janeiro e dos florescentes núcleos mineradores das Minas Gerais e de Goiás, eram abatidos por muitos extravios, perdas, e quando resistiam chegava magro, o que fazia decair o preço do produto. No caso do Piauí, as charqueadas surgiram, principalmente, na foz oriental do rio Parnaíba, às margens do seu afluente Igarassu, na região conhecida como Porto das Barcas, onde teve início a Vila de São João da Parnaíba.

Até antes de 1711, as atividades dos jesuítas no sertão piauiense eram missóes esporádicas, marcadas apenas por atividades de passagem que atravessavam a região entre o Maranhão e o Ceará, sendo reconhecidos poucos aldeamentos, como foi o caso dos estabelecidos às margens dos rios Longá, Poti e Aroazes. Também são poucas as informaçôes sobre trabalhos vinculados à catequese e à educação. Após a herança de Mafrense, e por meio do trabalho dos negros e indígenas domesticados, da isenção de taxas e impostos, os padres revelaram-se hábeis na administração, vendendo e comprando gado, bem como outras fazendas, expandindo seu patrimônio. Dentre elas, já se tem informaçóes de duas das fazendas aqui tratadas, a Serra Negra e a Água Verde (OLIVEIRA, ASSIS, 2009).

Contudo, em 1758, a Coroa Portuguesa decretou a expulsão da Companhia de Jesus de todo o Império. Oliveira e Assis (2009) contam que, em 1760, os jesuítas do Piauí foram presos e remetidos à Bahia. De acordo com Lima (2005), ainda em 1759, as fazendas passaram para a Real Administração, sendo denominadas Fazendas do Fisco ou Fazendas 
Reais. Após a Proclamação da Independência, elas passaram a incorporar o patrimônio do Império.

Em meados do século XVIII, a Coroa percebeu a necessidade de maior domínio do território. Assim, diante das grandes extensóes de terra, da força da Casa da Torre e dos padres jesuítas, expedidas de modo conveniente às injustiças e violência nos sertóes, e ainda da pouca fiscalização e dificuldades de administração pela Coroa, em 1761, quase cinquenta anos após a instalação da Vila de Nossa Senhora da Vitória, uma Carta Régia autorizou a fundação de novas vilas na Capitania de São José do Piauí e transformou a única vila já existente, a Vila da Môcha, em cidade, cujo nome foi substituído por Oeiras, em homenagem ao Primeiro Ministro do Reino, Conde da cidade portuguesa de Oeiras, o Marquês de Pombal.

Em 1762, quando já existiam cerca de 536 fazendas de gado, a criação das vilas incentivou a vida urbana, a reorganização social, o tratamento urbanístico, sobretudo através da implantação de equipamentos necessários, como o pelourinho, casas de câmara e cadeia e ainda residências, a regularização das atividades pastorais e fiscais, a redução das distâncias entre os moradores e a adoção de administradores nas fazendas, papel desempenhado em maioria pelos vaqueiros. A ideia era criar um movimento entre área rural e a urbana, dita civilizada, impulsionando as trocas comerciais interiores e exteriores, com outras capitanias, e assim, a economia da colônia. Recorde-se que, desde o início, a ocupação do Piauí foi pautada no absenteísmo, nas terras entregues a vaqueiros ou arrendatários, cujos lucros voltavam-se ou para mais aquisição de terras ou aplicados fora do Piauí, onde de fato esses proprietários moravam.

Em 1772, existiam, segundo Silva Filho (2007), 578 fazendas de gado. Contudo, a partir da segunda metade do século XVIII, o comércio do charque começou a perder em função da decadência do mercado minerador e da grande seca que ocorreu no Estado em 1777, uma estiagem de dois anos que reduziu significativamente a produção do charque. Além disso, seguiu-se uma epidemia de varíola, provocando a mortandade de dezenas de milhares de pessoas e, por fim, a forte concorrência mercantil, ocasionada pela entrada no mercado dos criatórios da Ilha de Marajó e do Rio Grande do Sul, que, no território das missóes, contava com maior segurança hídrica e melhores pastagens, o que fez o gado dos pampas conquistar mercados das regióes auríferas, de Sáo Paulo e do Rio de Janeiro, marcando o Movimento do Tropeirismo, cujo principal entreposto comercial era a vila paulista de Sorocaba (IPHAN, 2009).

O negócio da charqueada também tomou impulso no Rio Grande do Sul e, aliado a outra grande seca no sertáo, essa em 1791, muitas charqueadas do Nordeste entraram em ruínas, como a de Aracati, no Ceará. No Piauí, ela veio com menos força, garantindo ainda condições de comércio entre as charqueadas de Parnaíba com o Pará, Maranhão, Pernambuco e Bahia.

Ainda no final dos mil e setecentos, a pecuária sertaneja dá sinal de seus maus momentos, cada vez mais restrita ao comércio da carne verde e subordinada a mercados em declínio. Ao mesmo tempo, do Maranhão a Pernambuco iniciaram o cultivo do algodão em escala comercial para exportação, mudando a configuração comercial até então desenvolvida, 
voltada para o mercado de víveres. Dessa forma, algumas das antigas fazendas piauienses também passaram a se dedicar ao algodáo e a outros produtos, como o fumo.

Para se ajustar ao mercado, em meados do século XIX, o Piauí partiu em busca de outra atividade comercial, através do comércio de exportação, feito via navegação fluvial e marítima, aproveitando a estrutura já existente em Parnaíba, no Porto das Barcas, antes direcionada ao charque, mas que, a partir daquele momento, voltou-se para o comércio do algodão, fumo, couro e outras sementes extrativistas, dando início a um novo período de desenvolvimento, o que impôs às fazendas uma mudança de configuração, inclusive arquitetônica. A pecuária, em grave crise, não teria capacidade de impulsionar a economia da capitania dentro da nova conjuntura dos mercados mundiais que se apresentava na virada do século XVIII para o século XIX.

É importante frisar aqui a chegada da Corte ao Brasil, em 1808, que transformou a condiçấo de Colônia e implicou favoravelmente o estímulo ao desenvolvimento urbano, em especial, dos centros litorâneos, cujo contato com o exterior era maior. Pode-se dizer que se tem aí o início de um novo projeto de modernizaçáo que, segundo Freire (1948), foi reforçado pelo imperativo inglês que impôs ao Brasil a mudança de hábitos e valores, provocada pelo consumo de produtos, como a manteiga, a cerveja, os tecidos, as porcelanas, os perfumes; enfim, produtos que logo foram incorporados e consumidos pelos que detinham uma situação econômica mais privilegiada; e mesmo com muitas dificuldades, essas inovações, aos poucos e de modo singelo, alcançam o sertão e as antigas fazendas.

A intensa concentração de propriedade da terra como pressuposto básico da criação extensiva que marcou o período colonial no Piauí perdurou mesmo após mudanças políticas que seguiram. Com o tempo, poucas famílias mantiveram-se como as detentoras dessas grandes áreas, em sua maioria, ligadas por laços de consanguinidade.

Em 1850, o conselheiro Antônio Saraiva, ao assumir o governo da Província, escolheu um novo local para fundar a nova capital do Piauí, nas proximidades da Vila Nova do Poti, antes conhecida como a Chapada do Corisco, e entáo chamado de Teresina, em homenagem à Imperatriz Teresa Cristina (ADRIÃO NETO, 2004).

O início da navegação a vapor no rio Parnaíba, em 1859, impulsionou o crescimento urbano da nova capital, transformando-se em importante eixo comercial, e, como acentua o IPHAN (2009), marcando de modo acentuado a mudança da configuraçáo de antes, curral e igreja, pelo esquema cais e comércio, favorecendo o aparecimento e o impulso de outros núcleos urbanos ao longo do rio, como as cidades de Floriano e Amarante. A fundação de Teresina marcou o desfecho do longo processo histórico de declínio da pecuária extensiva, atividade econômica que determinou a ocupação destes sertôes e a criação da capitania do Piauí. (IPHAN, 2009).

Naquele momento recursos federais subsidiavam a construção da nova capital e a implantação de uma estrutura econômico-social atrelada à bacia do Parnaíba. Ao fim do Império, Braz (2007) afirma que a estrutura socioeconômica do Estado, como durante o período Colonial, perdurou baseada nos grandes proprietários de terra, seguidos por arrendatários, pequenos comerciantes e um número irrelevante de profissionais liberais, encarregados de fazendas e escravizados. 


\section{Conclusão}

Destacou-se aqui a história e a contextualização das fazendas do Piauí. O objetivo do artigo foi apresentar o contexto geral das fazendas do Piauí, fundadas entre os séculos XVII e XX a partir da arquitetura e das relaçóes históricas entre os diversos sujeitos e espaços, por meio da compreensão dos aspectos contextuais. No que diz respeito ao meio ambiente, chama-se a atenção para o processo de apropriação das terras ao longo da história piauiense, que se caracterizou pelo desbravamento da regiáo, insistindo sempre em açóes como a devastação, o desmatamento, como forma de posse e a valorização da terra. No final do século XX, mesmo com grande aporte tecnológico, surgiu na região Sul do Piauí um novo modelo de fazenda, mesmo assim, baseado em aspectos muito tradicionais. Como no resto do mundo, somente a partir dos anos 1960 e 1970, a preocupação referente a meio ambiente, patrimônio e paisagem cultural vem à tona de maneira enfática. Contudo, as ações e reflexos dessa preocupação são muito mais lentas, e se deparam sempre com questóes aparentemente contraditórias, como desenvolvimento e sustentabilidade.

Ao se analisar paisagem cultural, discutir sobre o patrimônio, deve-se lembrar de que não são apenas os aspectos materiais que os compóem, que não se deve pensar em manter apenas a dimensão material, mas ainda, seus valores, pois são esses que o caracterizam como representativos de um grupo, de um tempo, de uma história. A preservação dos bens patrimoniais, da paisagem cultural, cabe a todos, tornando-se essencial para a evolução da humanidade, para que esta viva de forma harmônica, respeitosa, tanto com a história quanto com a natureza, e siga na busca por liberdade, conhecimento e qualidade de vida.

Ressalte-se, mais uma vez, a importância do presente estudo, por meio do qual se busca entender, através da história piauiense e suas nuances - políticas, econômicas, sociais e culturais - a paisagem cultural, por sua vez conformada pela união entre meio ambiente e arquitetura, e quais serão os possíveis caminhos para se pensar ambiente e natureza de forma global, buscando despertar para estratégias de uso e manejo do solo, onde economia e ecologia caminhem de forma harmônica.

\section{Referências}

ABREU, Capistrano de. Capítulos de história colonial (1500-1800). 5. ed. Rio de Janeiro: Livraria Briguet, 1969.

\section{ABREU, Capistrano de. Capítulos de história colonial e os caminhos antigos e o povoamento do Brasil. 2. ed. Brasília: UNB, 1998.}

ADRIÃO NETO. Geografia e história do Piauí para estudantes: da Pré-História à atualidade. 3. ed. Teresina: Geração 70, 2004.

ALVES, Vicente Eudes Lemos. As bases históricas da formação territorial piauiense. Geosul, Florianópolis, v.18, n.36, p.55-76, jul./dez. 2003. Disponível em: < http://www. periodicos.ufsc.br/index.php/geosul/article/viewFile/13577/12450>. Acesso em: 18 abr. 2019. 
ARRAES, Esdras. Plantar povoações no território: (re)construindo a urbanização da capitania do Piauí, 1697-1761. Anais do Museu Paulista. São Paulo, n. sér. v. 24, n.1, p. 257-298, jan./ abr. 2016.

ASSIS, Nívea Paula Dias de. A Capitania de São José do Piauhy na racionalidade espacial pombalina (1750-1777). 169 f. Dissertação (Mestrado). Universidade Federal do Rio Grande do Norte, 2012. Disponível em: <https://repositorio.ufrn.br/jspui/ bitstream/123456789/16972/1/NiviaPDA_DISSERT.pdf>. Acesso em: 22 jun. 2019.

BRASIL. Portaria n. 127, de 30 de abril de 2009. Estabelece a chancela da Paisagem Cultural Brasileira. Diário Oficial da União. Brasília: Imprensa Nacional, 05 maio 2009. n. 83, Seção 1, p. 17.

BRANDÃO, Tanya Maria Pires. A elite colonial piauiense: família e poder. Teresina: Fundação Monsenhor Chaves, 1995.

BRANDÃO, Tanya Maria Pires. O escravo na formaçáo social do Piauí: perspectiva histórica do século XVIII. Teresina: UFPI, 1999.

BRAZ, Márcio. Inserção desvantajosa, atraso e subordinação das políticas de desenvolvimento na economia piauiense. Departamento de Ciências Econômicas da Universidade Federal do Piauí - v.1, n.12, a.7 (maio 2007) - Teresina: UFPI, 2007.

CARVALHO, Isabel Cristina de Moura. A invençáo ecológica: narrativas e trajetórias da educação ambiental no Brasil. 2. ed. Porto Alegre: EDUFRGS, 2002. p. 35-67.

CARVALHO, Isabel Cristina de Moura. Educaçáo ambiental: a formação do sujeito ecológico. São Paulo: Cortez, 2004.

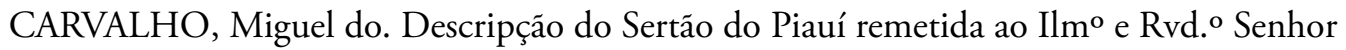
Frei Francisco de Lima, Bispo de Pernambuco (1697). In: ENNES, Ernesto. As Guerras nos Palmares. Rio de Janeiro: Nacional, 1938.

CEPRO - Fundação Centro Pesquisas Econômicas e Sociais do Piauí. Plano de desenvolvimento sustentável do Piauí - Macrotendências de investimento produtivo e em infraestrutura nos segmentos estratégicos - Produto 2, 2013. Disponível em: < http:// www.cepro.pi.gov.br/download/201608/CEPRO02_9b568b361f.pdf>. Acesso em: 24 jun. 2019.

CHAVES, Joaquim Raimundo Ferreira. Teresina: subsídios para a História do Piauí. Teresina: Fundação Cultural Monsenhor Chaves, 1994.

CORRÊA, Guilherme Carlos; PREVE, Ana Maria. A educação e a maquinaria escolar: subjetividades, biopolíticas e fugas. Revista de Estudos Universitários REU, Sorocaba, SP, v. 37, n. 2, 2002. 
FRANCO, José Patrício. O município do Piauí: 1761 a 1961. Edição comemorativa aos 125 anos de Teresina [s. n.], 1977.

FREIRE, Gilberto. Ingleses no Brasil. Rio de Janeiro: José Olympio, 1948.

IPHAN, Instituto do Patrimônio Histórico e Artístico Nacional. Cidades do Piauí testemunhas da ocupação do interior do Brasil durante o século XVIII. Conjunto histórico e paisagístico de Oeiras: dossiê de tombamento. Murilo Cunha Ferreira (Org.). Teresina, 2009.

JUCÁ NETO, Clovis Ramiro. A urbanizaçáo do Ceará setecentista: as vilas de Nossa Senhora da Expectação do Icó e de Santa Cruz do Aracati. 2007. Tese (Doutorado em Arquitetura e Urbanismo) - Faculdade de Arquitetura, Universidade Federal da Bahia, Salvador 2007.

MOTT, Luiz R. B. Piauí colonial; população, economia e sociedade. Teresina: Projeto Petrônio Portela, 1985.

NASCIMENTO, Flávia B.; SCIFONI, Simone. A paisagem cultural como novo paradigma para a proteção: a experiência do Vale do Ribeira-SP. Revista CPC (USP). São Paulo, v. 10, p. 29-48, 2010. Disponível em: <http://portal.iphan.gov.br/uploads/ ckfinder/arquivos/Texto\%205\%20\%20NASCIMENTO\%20e\%20SCIFONI.pdf>. Acesso em: 2 set. 2016.

NUNES, Odilon. Pesquisas para a história do Piauí. v. 1. Rio de Janeiro: Artenova, 1975.

NUNES, Odilon. Depoimentos históricos. Teresina: COMEPI, 1981. p. 11.

OLIVEIRA, Ana Stela de Negreiros; ASSIS, Nívia Paula Dias de. Padres e Fazendeiros no Paiuí Colonial - Século XVIII. ANPUH - XXV Simpósio Nacional de História. Fortaleza, 2009.

OLIVEIRA, Ana Stela. O povoamento colonial do Sudeste do Piauí: indígenas e colonizadores, conflitos e resistência. 2007 Tese (Doutorado) - UFPE, Recife, 2007.

PIAUÍ. Lei Estadual n. 3320, de 04 de abril de 1975. Diário Oficial do Estado. Teresina: COMEPI, 07 jul. 1975. n. 118, p. 02.

PIAUÍ. Decreto n. 2967-A, de 1978. Diário Oficial do Estado. Teresina: COMEPI, 31 jul. 1978. n. 143, p. 61-67.

POMPA, Maria Cristina. História de um desaparecimento anunciado: as aldeias missionárias do São Francisco, séculos XVIII - XIX. In: OLIVEIRA, João Pacheco de (Org.). A presença indígena no Nordeste: processos de territorialização, modos de relacionamento e regimes de memória. Rio de Janeiro: Contra Capa, 2011. 
PORTO, Carlos Eugênio. Roteiro do Piauí. Rio de Janeiro: Artenova, 1974.

RODRIGUES, Joselina Lima Pereira. Estudos regionais - Geografia e História do Piauí. 3. ed. Teresina: Halley, 2005.

SANTANA, Raimundo Monteiro de. Evoluçáo histórica da economia piauiense. Teresina: Cultura, 1964.

SANTANA, Raimundo Monteiro de. Evoluçáo histórica da economia piauiense e outros estudos. Teresina: FUNDAPI, 2008.

SANTOS, Clóvis do. O espírito do capitalismo na ocupação dos cerrados brasileiros nos Estados da Bahia e do Piauí. Revista de Geografia e Ordenamento do Território GOT, Porto, n. 8, p. 229-253, dez. 2015. Disponível em: <http://www.scielo.mec.pt/scielo. php?script=sci_arttext\&pid=S2182-12672015000200013\&lng=pt\&nrm $=$ iso $>$. acessos em 25 jun. 2019.

SILVA, Francisco Carlos Teixeira da. Histórias das Paisagens. In: CARDOSO, Flamarrion Ciro; VAINFAS, Ronaldo. Domínios da história: ensaios de teoria e metodologia. Rio de Janeiro: Elsevier, 1997.

SILVA FILHO, Olavo Pereira da. Carnaúba, pedra e barro na Capitania de Sáo José do Piauí. Belo Horizonte: Ed. do Autor, 2007.

SILVA, Francisco Carlos Teixeira da. Pecuária e formação do mercado interno no Brasilcolônia. In: Estudos Sociedade e Agricultura, 8, abril 1997, p. 119-156. Disponível em: <http: https://revistaesa.com/ojs/index.php/esa/article/view/108/104>. Acesso em: 22 jun. 2019.

SOUSA, Valfrido Viana de. SOUSA, V. V. Piauí: Apossamento, desenvolvimento e integração (1684-1877). I Seminário de Pesquisa da Pós-Graduação UFG/UCG, Goiânia, 2008, v. 01. p. 1-26. Disponível em: <https://pos.historia.ufg.br/up/113/o/43_ ValfridoSousa_PiauiApossamentoIntegracao.pdf>. Acesso em: 24 jun. 2019.

SPIX, Johann Baptist von; MARTIUS Carl Friedrich Philipp von. Viagem pelo Brasil: 1817-1820. Belo Horizonte: Itatiaia; São Paulo: Universidade de São Paulo, 1981. V.2 Coleção Reconquista do Brasil.

TAVARES, Zózimo. O Piauí no século 20. 100 fatos que marcaram o Estado de 1900 a 2000. Teresina: Alínea, 2003. 